\title{
PERANCANGAN SISTEM PENGELOLAAN INVENTARIS BARANG SARANA DAN PRASARANA DI SMKN 7 BEKASI
}

\author{
Mauliandika Suswara ${ }^{1}$, Indra Kurniawan ${ }^{2}$ \\ Program Studi Teknik Informatika, Fakultas Teknik dan Ilmu Komputer, \\ Universitas Indraprasta PGRI \\ Jalan Raya Tengah No 80, Kelurahan Gedong, Pasar Rebo, Jakarta Timur \\ dikacarter@gmail.com ${ }^{1}$, inkur.master@gmail.com²
}

\begin{abstract}
Abstrak
Teknologi komputer merupakan suatu yang sangat didambakan oleh setiap organisasi, karena akan mengeluarkan suatu informasi yang sempurna. kebutuhan komputer sebagai alat pemecahan masalah dengan cepat dan tak bisa dipungkiri. Pendataan barang inventaris yang dilakukan pada SMK Negeri 7 Bekasi masih dilakukan secara manual dengan menggunakan aplikasi microsoft word dan Microsoft excel. Pendataan manual dengan cara ini dapat mempersulit staf sarana dan prasarana ketika melakukan pendataan inventarisasi barang dan pembuatan laporan, sehingga dapat memakan waktu yang banyak ketika membuat laporan saat dibutuhkan. Tujuan dari penelitian adalah membuat sistem informasi yang dapat melakukan pengontrolan stok barang disekolah sehingga dapat memberitahukan tentang jumlah stok barang yang ada disekolah dengan cepat dan akurat dan menyajikan pemrosesan data tentang barang yang masuk dan keluar dengan cepat dan akurat. Penelitian ini dilakukan dengan menggunakan metode grounded research yaitu sebuah metode yang dilakukan berdasarkan fakta yang sebenarnya. Dari hasil pengujian yang telah dilakukan, penulis menyimpulkan bahwa Perancangan Sistem Pengelolaan Inventaris Barang Sarana dan Prasarana ini dapat membantu keakuratan dalam kegiatan pengelolaan inventaris barang serta dapat memperbaiki laporan menjadi lebih terlihat rapih. Dimana dalam membangun sistem ini digunakan bahasa pemrograman JAVA dengan Netbeans IDE, dan database MYSQL menggunakan XAMPP.
\end{abstract}

Kata Kunci: Perancangan, Inventaris Barang, Sarana dan Prasarana, Java Netbeans

\begin{abstract}
Computer technology is something that is highly coveted by every organization, because it will release a perfect information. The need for a computer as a problem solve tool quickly and undeniably. The collection of inventory items carried out in SMK Negeri 7 Bekasi is still done manually using microsoft word and Microsoft excel applications. Manual data collection in this way can make it difficult for facilities and infrastructure staff when recording inventory of goods and making reports, so it can take a lot of time when making reports when needed. The purpose of the research is to create an information system that can control the stock of goods in school so that it can inform about the amount of stock of goods in school quickly and accurately and present data processing about goods entering and exiting quickly and accurately. This research is done using the grounded research method which is a method that is done based on actual facts. From the results of the tests that have been done, the author concluded that the Design of Inventory Management System of Goods facilities and infrastructure can help accuracy in inventory management activities and can improve the report to look neater. Where in building this system used the JAVA programming language with Netbeans IDE, and MYSQL databases use XAMPP.
\end{abstract}

Keywords: Design, Inventory of Goods, Facilities and Infrastructure, Java Netbeans

\section{PENDAHULUAN}

Teknologi Informasi adalah "suatu teknologi yang digunakan untuk mengolah data yang dimana pengolahan itu termasuk memproses, mendapatkan, menyusun, menyimpan, memanipulasi data dalam berbagai cara untuk menghasilkan informasi yang berkualitas, yaitu informasi yang relevan, akurat dan tepat waktu”. (Hamzah, B. Uno, 2011)Komputer saat ini merupakan kebutuhan manusia di dalam melakukan berbagai kegiatan ditambah dengan adanya teknologi informasi yang semakin berperan di dalam dunia pekerjaan. Dengan menggunakan teknologi informasi akan menghasilkan informasi yang tepat dan akurat sesuai dengan kebutuhan sehingga dapat diambil dengan cepat. Penerapan standar sarana dan prasarana adalah peningkatan mutu standar nasional pendidikan yang berkaitan dengan kriteria minimal tentang ruang belajar, tempat berolahraga, tempat beribadah, 
perpustakaan, laboratorium, bengkel kerja, tempat bermain, tempat berkreasi dan berekreasi serta sumber belajar lain, yang diperlukan untuk menunjang proses pembelajaran, termasuk penggunaan teknologi dan komunikasi.

Menurut (Gunawan, 2011). Inventarisasi Sarana dan Prasarana Pendidikan adalah kegiatan untuk mencatat dan menyusun daftar barang-barang yang ada secara teratur menurut ketentuan yang berlaku. Pendataan barang inventaris yang dilakukan pada SMK Negeri 7 Bekasi masih dilakukan secara manual dengan menggunakan aplikasi microsoft word dan Microsoft excel. Pendataan manual dengan cara ini dapat mempersulit staf sarana dan prasarana ketika melakukan pendataan inventarisasi barang dan pembuatan laporan, sehingga dapat memakan waktu yang banyak ketika membuat laporan saat dibutuhkan. Selain itu terjadinya pergantian staf sarana dan prasarana yang seringkali membuat laporan yang akan dibuat menjadi tidak kontinu dalam pengisian data inventaris barang dan program sehingga membuat data tidak terbarui.

Berdasarkan permasalahan diatas peneliti merasa tertarik untuk melakukan penelitian dengan judul Perancangan Sistem Pengelolaan Inventaris Barang Sarana dan Prasarana Berbasis Java pada SMKN 7 Bekasi.

\section{PENELITIAN RELEVAN}

Dalam melakukan penelitian tentang judul Perancangan Sistem Pengelolaan Inventaris Barang Sarana dan Prasarana Berbasis Java pada SMK Negeri 7 Bekasi, peneliti menggunakan bahan referensi, antara lain dari penelitian terdahulu, dan beberapa buku yang menunjang untuk data-data penelitian. Adapun penelitian yang di ambil yaitu :

Penelitian dari (Witama, 2019) berjudul Perancangan Aplikasi Pengelolaan Aset Barang Inventaris SDN Makasar 05 Pagi Jakarta Timur. Tujuan dari penelitian ini adalah untuk merancang dan membuat sebuah sistem aplikasi pengelolaan asset barang pada SDN Makasar 05 Jakarta Timur yang awalnya masih menggunakan proses manual menjadi sebuah sistem yang lebih cepat, modern, dan lebih mudah dalam penggunaannya dengan menggunakan bahasa pemrograman Java.

Penelitian dari (Sari\&Nuari, 2017) yang berjudul "Rancang Bangun Sistem Informasi Persediaan Barang Berbasis Web Dengan Metode FAST (Framework For The Applications)". Tujuan dari penelitian ini adalah untuk merancang sebuah sistem informasi berbasis web sebagai solusi permasalahan yang timbul dari pengolahan data secara manual. Dengan merubah sistem menjadi terkomputerisasi, diharapkan pengelolaan persediaan barang menjadi lebih efektif dan efisien, penyajian laporan persediaan barang menjadi lebih akurat dan tepat waktu.

\section{METODE PENELITIAN}

Desain penelitian yang digunakan penulis adalah metode grounded (grounded research) yaitu Suatu metode penelitian berdasarkan pada fakta dan menggunakan analis perbandingan dengan tujuan menetapkan konsep, membuktikan teori, mengembangkan teori, pengumpulan, dan analisis data dalam waktu yang bersamaan (Nazir, 2011).

Untuk menyempurnakan hasil dari penelitian ini, penulis mencoba menuliskan langkah-langkah yang dilakukan dalam perancangan sistem Pengelolaan Inventaris Barang Sarana dan Prasarana. Langkah-langkah pengembangan sistem yang penulis gunakan adalah metode Waterfall. Dimana pengertian "Waterfall adalah suatu proses pengembangan perangkat lunak berurutan, dimana kemajuan dipandang sebagai terus mengalir ke bawah (seperti air terjun) melewati fase-fase perencanaan, permodelan, implementasi (konstruksi), dan pengujian "(Adam et al., 2019). Dalam pengembangannya metode waterfall memiliki beberapa tahapan yaitu :

1. System Enginering (Persiapan Data)

Dalam tahap ini penulis melakukan pengumpulan data kebutuhan seluruh elemen sistem seperti data-data yang digunakan. Dimana elemen itu dapat menunjang perkembangan Perancangan Sistem Pengelolaan Inventaris Barang Sarana dan Prasarana Pada SMK Negeri 7 Bekasi. 
2. Analysis (Analisa Data dan Proses)

Kemudian penulis menganalisa kebutuhan, pada tahapan ini data dan informasi yang didapat akan digunakan untuk mengolah rancangan system di SMK Negeri 7 Bekasi. Sebelum merancang sebuah sistem kita harus memahami kebutuhan yang di perlukan, seperti : Menentukan profil perusahaan, Menganalisa tugas-tugas yang dikerjakan, Menganalisa data masukan, Menganalisa proses yang berjalan atau proses yang digunakan.

3. Design (Perancangan Sistem)

Setelah analisis kebutuhan, tahap selanjutnya perancangan sistem di SMK Negeri 7 Bekasi yang bertujuan untuk merancang sistem yang akan dibuat agar dapat diimplementasikan dengan kebutuhan pegawai SMK Negeri 7 Bekasi. Langkah-langkah yang dilakukan dalam proses pendataan stok barang ini adalah Merancang Basis Data (Database), Merancang kode-kode pada software yang di gunakan dan Merancang Antarmuka.

4. Coding (Pengkodean)

Pada tahap ini di buat coding Perancangan Sistem Pengelolaan Inventaris Barang Sarana dan Prasarana Pada SMK Negeri 7 bekasi dibuat kedalam aplikasi Neatbeans 8.0.2 dengan Bahasa pemograman Java, Java adalah bahasa pemrograman berorientasi objek yang dapat digunakan untuk pengembangan aplikasi mandiri, aplikasi berbasis internet maupun intranet serta aplikasi untuk perangkat-perangkat cerdas yang dapat berkomunikasi lewat intranet / jaringan komunikasi. (Nyura, 2010). Sebagai bahasa pemogramman, Netbeans merupakan sebuah aplikasi Integrated Development Environment (IDE) yang berbasiskan Java dari Sun Microsystems yang berjalan di atas Swing dan banyak digunakan sekarang sebagai editor untuk berbagai bahasa pemrograman (Nofriadi, 2018) .MySQL untuk membuat database MySQL adalah sebuah perangkat lunak sistem manajemen basis data SQL atau yang lebih dikenal dengan Database Management System (DBMS)(Huda \& Komputer, 2010). serta XAMMP sebagai penghubung server database.

5. Testing (Pengujian)

Setelah perancangan sistem, Penulis melakukan pengujian sebelum sistem pendataan stok barang dapat digunakan dengan baik. Rangkaian pengujian ini dijalankan bersama-sama dengan data actual dari sistem yang sedang berjalan. di SMK Negeri 7 Bekasi agar mengetahui aplikasi yang telah dibuat sudah layak dipakai atau belum. Aplikasi ini di uji langsung oleh Staff Sarana dan Prasarana SMK Negeri 7 Bekasi, mulai dari masukkan data sampai keluaran data

6. Maintenance

Setelah tahapan pengujian system, maka tahapan terakhir adalah maintenance atau pemeliharaan. Maintenance dilakukan secara berkala baik dalam membackup data maupun memeliharan system yang dibangun secara berkala serta melakukan perbaikan system agar system dapat bekerja secara baik dan optimal.

\section{HASIL DAN PEMBAHASAN}

Aturan sistem pendataan persediaan yang akan diusulkan di SMK Negeri 7 Bekasi pada perancangan inventaris barang sarana dan prasarana adalah :

a. Setiap barang yang di kirim oleh supplier/rekanan segera di input ke dalam transaksi barang masuk untuk ditambahkan ke dalam persediaan barang dan data supplier oleh staf sarana dan prasarana.

b. Staf Sarana dan Prasarana mengecek persediaan barang yang sudah ada di data persediaan barang

c. Staf Sarana dan Prasarana menyerahkan barang yang ada dipersediaan barang kepada Guru dan Staf Tata Usaha

d. Kepala Sekolah menerima laporan data persediaan barang, data supplier, data barang masuk dan data serah terima barang 
Berikut ini merupakan penggambaran Dekomposisi fungsi sistem yang diusulkan pada perancangan sistem pengelolaan inventaris barang sarana dan prasarana pada SMK Negeri 7 Bekasi.

\section{Dekomposisi Fungsi Sistem yang Diusulkan}

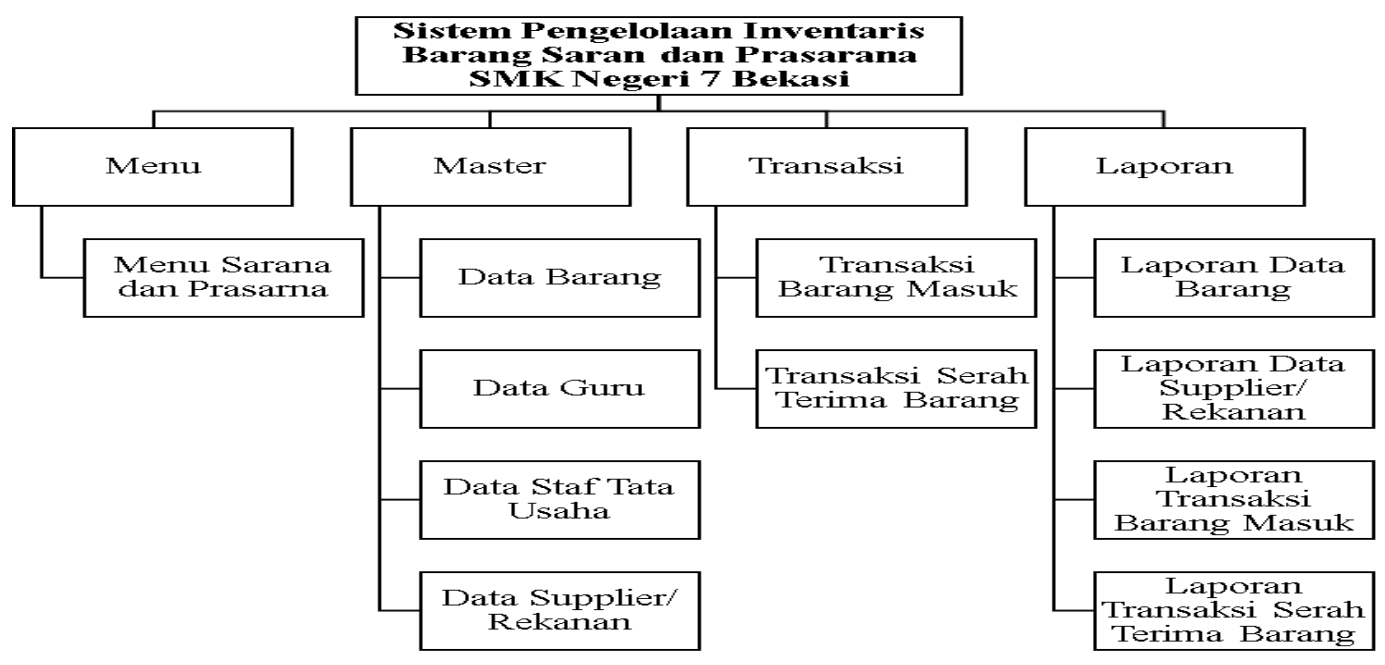

Gambar 1. Dekomposisi Sistem yang Diusulkan

Dekomposisi fungsi dimulai dengan analisis pekerjaan yang ingin dilakukan, diikuti tahap penyimpanan dengan menyimpan nama-nama guru dan staf tata usaha, nama-nama supplier/rekanan, transaksi barang masuk,transaksi barang masuk, transaksi serah terima barang dan pembuatan laporan, menggambarkan dimana prosesnya mempermudah karyawan melakukan pendataan persediaan barang masuk dan keluar. Dekomposisi Diagram sistem pendataan persediaan pada SMK Negeri 7 Bekasi sebagai berikut :

\section{Use Case Diagram}

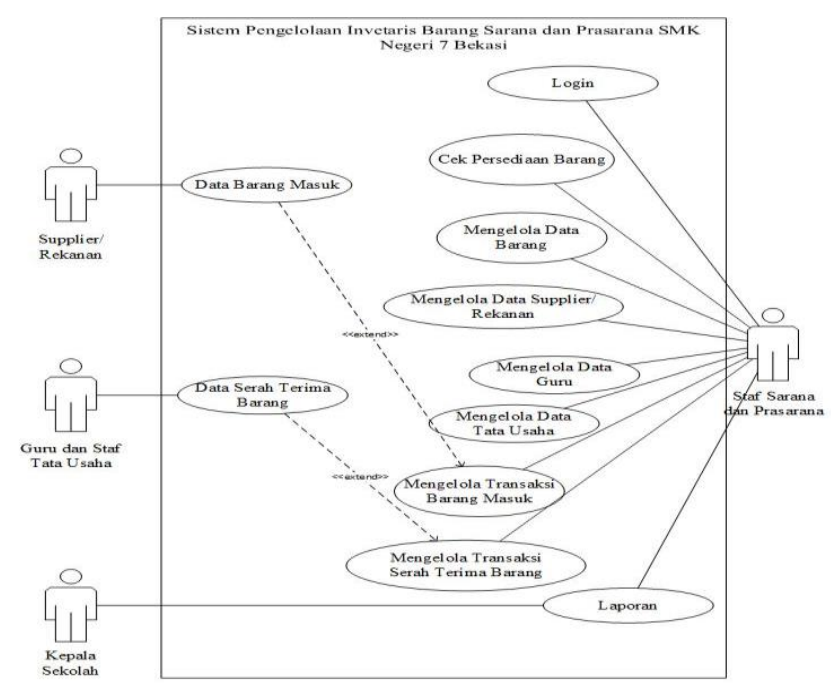

Gambar 2. Use Case Diag 
Diagram use case mendeskripsikan sebuah interaksi antara satu atau lebih aktor dengan sistem yang dibuat. (Harianto, 2019)

\section{Rancangan Tampilan Layar}

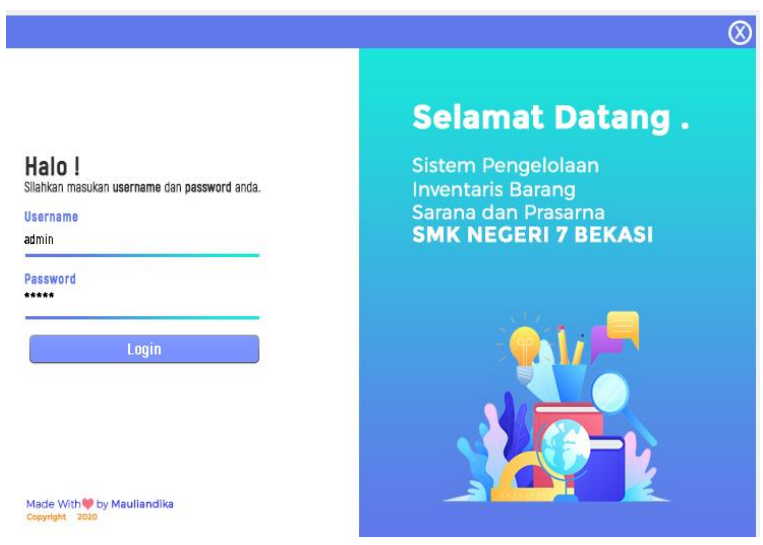

Gambar 3. Tampilan Login

Tampilan login adalah tampilan keamanan sistem dimana pengguna yang tidak memiliki akses tidak dapat menggunakan sistem tersebut. Yang dapat menjalankan sistem hanyalah orang yang memiliki akses penuh terhadap sistem pengelolaan inventaris barang.

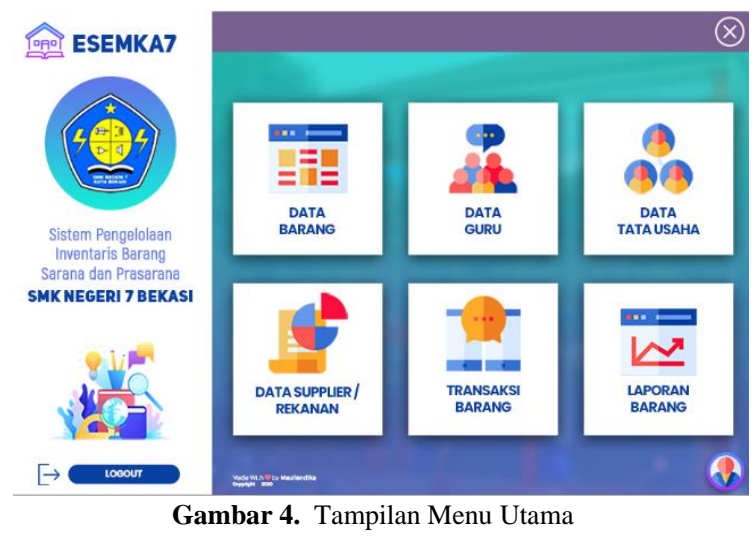

Tampilan menu utama adalah tampilan dasar program sistem inventaris barang yang dimana sebagai bagian penunjang untuk mengakses menu-menu lainnya. Pada tampilan menu utama terdapat Menu Data Barang Data Guru, Data Tata Usaha, Data Supplier, Transaksi Barang dan Laporan Barang serta terdapat tombol logout untuk kembali ke Tampilan Login.

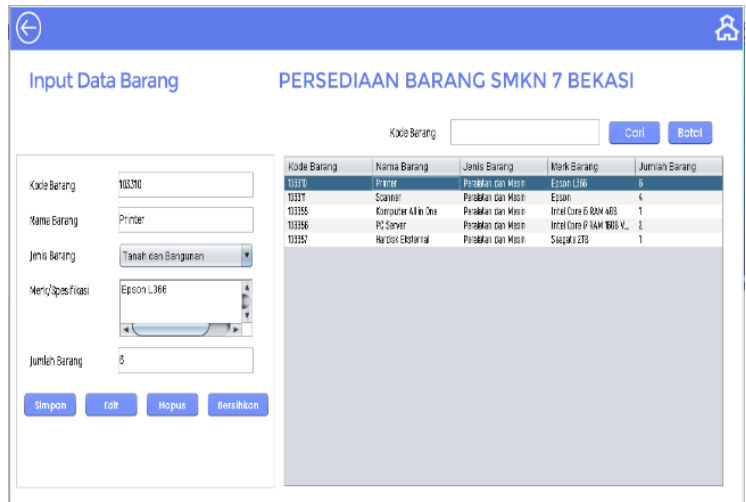

Gambar 5. Tampilan Input Data Barang 
Tampilan data persediaan barang adalah tampilan data barang yang dimana setiap barang masuk dari supplier otomatis masuk ke data persediaan barang dan masuk ke dalam database barang.

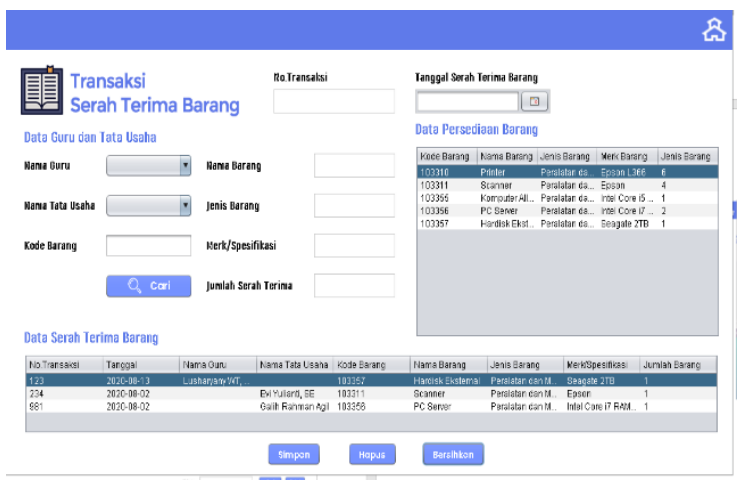

Gambar 6. Tampilan Serah Terima Barang

Tampilan data serah terima barang digunakan untuk melakukan pendataan barang yang ingin dierah terimakan kepada guru atau tata usaha dan data persediaan barang yang ada pada database barang secara otomatis, data serah terima otomatis dapat menghitung persediaan barang yang ada.

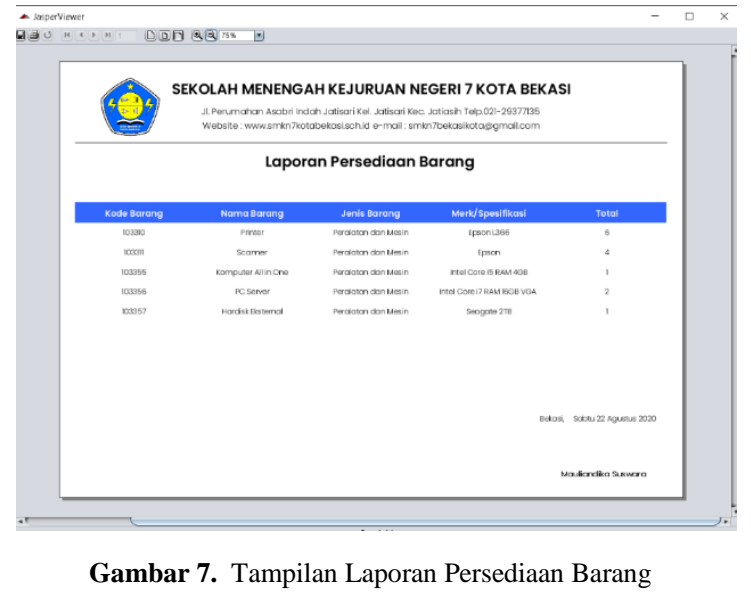

Tampilan laporan persediaan barang ini dibuat untuk laporan yang akan diserahkan kepada Kepala Sekolah sebagai bahan penilaian dan tertib administrasi.

\section{SIMPULAN}

Berdasarkan hasil dari pembuatan Perancangan Sistem Pengelolaan Inventaris Barang Sarana dan Prasarana Berbasis Java pada SMK Negeri 7 Bekasi, peneliti menyimpulkan :

SMK Negeri 7 Bekasi dalam menjalankan kegiatan administrasi tata usaha perlu adanya peranan teknologi informasi yang dapat membantu menangani kegiatan pendataan persediaan barang yang masih dilakukan secara manual yaitu seperti pencatatan data persediaan barang, barang masuk dari supplier/rekanan dan data serah terima barang, sehingga memungkinkan adanya kesalahan dalam pencatatan yang menyebabkan selisih data persediaan barang, Dalam proses perancangan sistem pengelolaan inventaris barang sarana dan prasarna di SMK Negeri 7 Bekasi ini menggunakan bahasa pemrograman Java dengan aplikasi Netbeans IDE 8.0.2 sebagai software dalam pembuatan programnya, sedangkan MySQL sebagai basis data, Adapun manfaat yang didapat dengan adanya pembuatan aplikasi pendataan persediaan barang yaitu lebih efektif dan menignkatakan keakuratan pekerjaan Staf Sarana dan Prasarana dalam melakukan pencatatan transaksi barang masuk dan transaksi serah terima barang serta dalam penginputan data persediaan barang, data supplier, data guru dan tata usaha serta pembuatan laporan. 


\section{DAFTAR PUSTAKA}

Adam, R. P., Abdillah, T., \& Pakaya, N. (2019). Sistem Informasi Bantuan Bahan Pustaka. Jambura Journal of Informatics. https://doi.org/10.37905/jji.v1i2.2729

Gunawan, A. H. (2011). Administrasi Sekolah Administrasi Pendidikan Mikro. Rineka Citra.

Hamzah, B. Uno, N. L. (2011). Teknologi Komunikasi dan Informasi Pembelajaran. PT Bumi Aksara.

Harianto, Kusno., dkk. (2019). Sistem Monitoring Lulusan Perguruan Tinggi Dalam Memasuki Dunia Kerja Menggunakan Tracer Study. Media Sahabat Cendikia.

Huda, M., \& Komputer, B. (2010). Membuat Aplikasi Database Dengan Java, MySQL dan NetBeans. Elex Media Komputindo.

Nazir. (2011). Metode Penelitian. Buku Beta.

Nofriadi. (2018). Java Fundamental Dengan Netbeans 8.02. Deepublish.

Nyura, Y. (2010). Pembuatan Aplikasi Pembelajaran Bahasa Inggris Pada Handphone dengan J2ME. Jurnal Informatika Mulawarman

Sari, A. O., \& Nuari, E. (2017). Rancang Bangun Sistem Informasi Persediaan Barang Berbasis Web Dengan Metode FAST (Framework For The Applications).

Witama, M. N. (2019). Perancangan Aplikasi Pengelolaan Aset Barang Inventaris SDN Makasar 05 Pagi Jakarta Timur. STRING (Satuan Tulisan Riset Dan Inovasi Teknologi). https://doi.org/10.30998/string.v3i3.3578 